\title{
Московский период Йиржи Вайла
}

\section{The Russian Period of Jiři Weil}

\author{
Рене Андрейс \\ (Оломоуц, Чешская Республика)
}

\begin{abstract}
:
The article reviews the works and personal reflections of Jiri Weil, one of the most prominent writer of Czech Avant-Garde who spent several years of his professional life in Soviet Moscow. The attention is mostly paid to the demonstration of the opinion transformation which can be found not only in Weil's own reflections but also in his prefaces of poetry anthologies or articles in Soviet newspapers. As a significant representative of Prague Avant-Garde groups and supporter of Russian emigrés, Weil was recognized as an expert on Russian literature and culture. Thanks to his professional knowledge of Russian language, he had opportunity not only to visit Soviet Russia for many times, but also to work for many years in the editorial office of Soviet journal. This experience represents the crucial moment in his views on Soviet reality. Restrictions and exhaustive routine led to negative reflections which were juxtaposed in his novel Moskva-hranice.
\end{abstract}

\section{Key words:}

Jiří Weil; Soviet Union; Czech Avant-Garde; Soviet reality; literature in Czechoslovakia; foreigners in the USSR 


\section{Введение}

Интернациональные, национальные и космополитические процессы в начале 20-х годов, результатом которых было, помимо прочего, стремление советской власти к диалогу с представителями интеллигенции, в том числе с представителями различных идейных кружков и платформ, тесно связаны с феноменом поездок в тогда формировавшуюся советскую Россию представителей европейской и американской интеллигенции. По оценке Майкла Дейвида-Фокса, советскую Россию в межвоенный период посетило 100 тысяч иностранцев [DAVID-FOX 2011, 1]. Несмотря на довольно объемный список литературы, посвященной проблематике восприятия нового социального и политического устройства (напр. Western Intellectuals and the Soviet Union Людмилы Стерн или The Pilgrimage to Russia Сильвии Маргулис), до сих пор в научной литературе не хватает обоснованного анализа ситуации с поездками в СССР чешских интеллигентов, который бы с помощью исторического контекста и архивного материала помог объяснить иногда намеренно искаженную интерпретацию таких поездок, в особенности в отношении публицистически ориентированных текстов.

С 1920 года, когда Россию в рамках организационной работы в Центральном бюро Чехословацкой коммунистической партии прибыл Иван Ольбрахт, до 1938 года, когда в Москву уже в очередной раз приезжает по приглашению ВОКС Марие Майерова, столицу посетили десятки писателей, художников, архитекторов, педагогов и теоретиков искусства. Их часто кратковременное пребывание в Советской России по-разному отражается в различных литературных формах в рамках многочисленных платформ. Диапазон идейных отношений к Советской России ограничивает, с одной стороны, коммунистическое движение, постепенно возникающее среди партии социал-демократов (Чехословацкая социал-демократическая рабочая партия), которое активно поддерживается коммунистами, и, с другой, антисоветским взглядом, представленным консервативно-национальной партией народных демократов (Чехословацкая народно-демократическая партия), которую тогда возглавлял Карел Крамарж. Стоит отметить, что, несмотря на разные политические взгляды чешских представителей власти, государство уже с 1922 г. заключает с Советским Союзом первые деловые договоры и устанавливает первое официальное представительство ЧСР в СССР, целью которого была поддержка политических, экономических и культурных связей. Параллельно в Чехословакии также возникает значительное количество объединений и организаций, ориентированных на Советскую Россию. Среди них можно выделить напр. Русский комитет для помощи голодающим, которые был организован при 
помощи Русской акции помощи - государственной программы помощи русским эмигрантам в Чехословакии, а также Общество для экономического и культурного сближения с Новой Россией (Společnost pro hospodářské a kulturní sblížení s Novým Ruskem), относившееся к объединениям левых интеллектуалов. Проблематика интерпретации и изложения материала заключается прежде всего не в количестве различных фактов, а скорее в проблеме фактичности, поскольку большинство рефлексий возникало на основе анализа сквозь призму того или иного мировоззрения, идейных убеждений и стремления показать и доказать критикам положительные элементы в жизни сформировавшегося субъекта. Кроме того, большое количество рефлексий тяготеет к фрагментарности, напоминающей форму путевых заметок при отсутствии контекста или комментариев.

Однако, среди информаторов и корреспондентов, которые прожили в стране довольно значительное время и тщательно следили за повседневностью, можно выделить одного из наиболее эрудированных экспертов по Советской России, чей опыт может послужить более глубокому анализу советско-чехословацких отношений в межвоенный период. Йржи Вайл (1900-1959) чешский писатель, переводчик и редактор, автор нескольких романов, прожил в Советской России несколько лет своей профессиональной жизни. Впервые он лично познакомился с советской реальностью в 1922 г., однако и до этого момента Вайл был близок к русской эмиграции, которой активно помогал. Об этом, в частности, свидетельствует его участие в советской миссии, в рамках которой он встречает в Праге редакцию еврейского журнала «Трибуна», в том числе С. С. Гиллерсона и Р. Якобсона [VONDRÁČKOVÁ 2014, 12]. В то время, будучи членом группы молодых коммунистических студентов, он посетил Россию в первый раз. Несмотря на ознакомительный характер поездки и высокий официальный уровень (Вайл принимает участие в Четвертом конгрессе Коммунистического интернационала) он успел познакомился с ведущими представителями авангарда - В. Маяковским, О. Бриком и Д. Бурлюком, с которыми регулярно встречался в квартире Маяковского и в литературном кафе в Настасьинском переулке. В обнаруженных в Архиве национальной письменности в Праге заметках Вайла, которые он вел во все время своей поездки, превалируют личные воспоминания о Маяковском. Кроме того, писатель подробно характеризует его сложное положение в писательской среде - Маяковский жалуется на бесконечные споры со сторонниками старой и «чистой» поэзии. По словам Вайла, Маяковский пользуется огромной популярностью среди молодежи и одновременно подвергается критике имажинистов, поэтов пролеткульта и поэтов возникшей в то время группы ЛЦК, в том числе Ильи Сельвинского. 
Судя по рассказу Бюст поэта [WEIL 1966, 12-18], который несет сильно автобиографический характер, Вайл успел познакомиться также с критиками Маяковского. В рассказе описывается прекращенное футуристами собрание имажинистов в Колонном зале [Дома Союзов] и неудачные поиски Есенина в штаб-квартире имажинистов - литературном кафе «Стойло Пегаса»: «Мы посмотрели под стол, и там, действительно, лежал поэт Сергей Есенин грязный, испачканный и лохматый». Первые московские встречи с русскими имажинистами и футуристами Вайл рефлектирует в книге Русская революциионная литература, в состав которой входят эссе о реализме, символизме, футуризме и новой прозе. Любопытно, что Вайл как один из первых чешских литературных критиков видит в русском футуризме чисто своеобразный стиль, подчеркивая, что, в отличие от напр. итальянского, русский футуризм тяготеет к народному искусству и прошлому [WEIL 1924, 28-29]. Критический тон Вайла чувствуется прежде всего в его заметках о будущих возможностях развития символистов и футуристов, где он не видит надежных перспектив, так как новая литература приближается к человеку (напр. введением в поэзию жанра частушки), между тем как символисты и футуристы исчерпали свои источники и постепенно становятся все более непонятными. Однако, стоит отметить, что революция не воспринимается автором как некий перелом, с которым прошлое уходит в забвение, а скорее как естественный процесс, порождающий новую поэзию: «Революция создала хаос, постепенно трансформирующийся в творческую деятельность. И эта деятельность продолжает развиваться против европейской литературы и превращается в чисто русскую форму. Результаты такой деятельности пока показывают только будущее направление [...] Таким образом, мировая литература опять начинает делиться на мировую и русскую» [WEIL 1924, 63-64]. Наряду с очерком о русской поэзии Франтишека Кубки (Поэты революционной России, 1924г.) и кратких эссе русской эмигрантки Надежды Филаретовны Мельниковой-Папоушковой, прибывшей в конце 1918 г. в Прагу (Антология русской поэзии, 1920 г., Очерки современной русской литературы, 1920 г.), можно говорить о первых в Чехословакии комплексных, хотя и небольших по объему, трудах, охватывающих дореволюционный и революционный период. Кроме того, ценным материалом являются авторские переводы Маяковского, Блока, Белого, Бабеля, Есенина и Мариенгофа, которые Вайл декламировал своим друзьям в авангардных кружках и стал, таким образом, известным популяризатором русской поэзии в Чехословакии. Вайл также являлся одним из первых в Чехословакии переводчиков поэзии символистов и футуристов на чешский язык. Данное первенство также объясняется тем, что, по словам Витезслава Незвала, Вайл был единственным представителем пражского авангарда, который владел русским языком [NEZVAL 1978]. 
С 1923 г. Вайл начинает работать в пресс-службе Советского представительства в Чехословакии. Кроме того, он публикуется в левых журналах «Рудэ право», «Пролеткульт» и «Новая Россия». Большинство его статей посвящено переводам русской прозы и поэзии. Кроме того, Вайл публикует несколько эссе о тенденциях новой революционной литературы. Учитывая идейную ориентацию журналов, обнаруживающуюся в большинство статей в форме использования характерной лексики эпохи, Вайл стремится обсуждать новую литературу с точки зрения естественного развития поэзии, так как современная поэзия развивается в том числе за счет влияния дореволюционной поэзии. Однако в некоторых статьях уже чувствуется, что Вайл, несмотря на свое глубокое знание русского языка и литературы, тяготеет к определенной идеологической окраске, что можно объяснить раличными намерениями и различной степенью официальности отдельных платформ - «Рудэ право» и «Пролеткульт» были официальными журналами Коммунистической партии Чехословакии, между тем как «Новая Россия» носит скорее информативный характер без идеологической окраски. Кроме журналистской и публицистской деятельности Вайл активно участвует в кружках пражской левой интеллигенции, таких как «Деветсил» или «Блок» и встречается с представителями русской эмиграции в Праге и Берлине (Цветаева, Пуни, Эренбург, Шкловский), с которыми обсуждает свои переводы поэзии Маяковского и Пастернака. Его профессиональный опыт и знание языка дает ему возможность организовать, совместно с Майеровой и Горой, визит Маяковского в Прагу в 1927 г., в рамках которого поэт выступил в Народном доме с лекцией о современной советской поэзии. Стоит отметить, что в том же году Прагу посетил и Бальмонт со своими лекциями, посвященными чешской поэзии и русским переводам чешского поэта Врхлицкого. Именно эти два поэта становятся символом противостояния двух идейных лагерей - с одной стороны, Бальмонт, сторонником которого был первый премьер-министр Чехословакии Карел Крамарж, остро выступавший против советской культурной экспансии, и, с другой стороны, Маяковский, приглашенный левыми писателями. Несмотря на удачное проведение визита Маяковского в Прагу, Вайл в своих архивных записках жалуется на отсутствие рефлексий поэта по отношению к Чехословакии: «Прагу Маяковксий очень любил. Все ему казалось очень близким, встречался с многими людьми, особенно с писателями и художниками. Однако в его творчестве ни о Праге, ни о Чехии практически невозможно ничего найти кроме нескольких стихов об особняке Крамаржа и пражских безработных и двух статей...». Вайл, по всей вероятности, имеет в виду следующее стихотворение Маяковского, в котором он как раз пародирует чешский язык и критикует сторонника Бальмонта Карла Крамаржа, женившегося в Крыму на 
Надежде Абрикосовой, где для них архитектор Котера построил т. н. «особняк Барбо»:

«Я до путешествий очень лаком.

Езжу Польшею,

по чехам,

по словакам. Не вылажу здесь из разговора вязкого

об исконном

братстве

племени славянского. Целый день,

аж ухо вянет, слышится: «словянами»... «словян»... «словяне»...

Нежен чех.

Нежней чем овечка.

Нет меж славян нежней человечка:

дует пивечко из добрых кружечек, и все в уменьшительном:

〈пивечко〉...

〈млечко〉...

Будьте ласков,

пан Прохаско...

пан Ваничек...

пан Ружичек... Отчего же господин Крамарж от славян

Москвы

впадает в раж?

Дело деликатнейшее, понимаете ли вы,

как же на славян

не злобиться ему?

У него

славяне из Москвы дачу

пооттяпали в Крыму. Пан Крамарж,

на вашей даче,

в санатории,

лечатся теперь

и Ванечки

и Вани,

которые

пролетарии,

конечно...

разные,

и в том числе славяне». 
После возвращения Маяковский также публикует краткие очерки из путешествий, среди которых обнаруживаются тексты «Немного о чехе» и «Чешский пионер» [MAJAKOVSKIJ 1958]. В первом из указанных рассказов Маяковский опять возвращается к теме Чехословакии: «Чехословакия одна из самых демократических, свободных политически стран. Здесь легальная компартия. Одна из сильнейших в Европе. Коммунистическая газета «Рудэ право» имеет около $1500 о$ тиража. Правда, здесь полная свобода и белым. Недаром - это центр российской эмиграции. В славянском кабачке сиживает и сам Чернов».

В те же годы Вайл публикуется в журналах «Кмен», «Розправы Авентина», «Нова Свобода» и «Ревю Деветсилу», где в публикациях он разрабатывает тему русской авангардной поэзии и прозы, а также творчества Горького и Бабеля. Кроме того, Вайл в своих статьях постулирует довольно оригинальный подход к переводам русской литературы на чешский язык, критикуя использование чешскими переводчиками русизмов, которые у читателя вызывают непонимание и эффект остранения. По его словам, правильного перевода и удачной передачи текста можно достичь только с помощью применения русского синтаксиса в конкретных случаях...» [WEIL 1928, 53-54].

В третий раз Вайл приезжает в Москву в 1933г., когда помимо работы в Издательском товариществе иностранных рабочих в СССР в качестве переводчика марксисткой литературы он участвует в субботниках на стройке московского метрополитена. Несмотря на наличие многочисленных статей информативного характера, опубликованных в те годы в чешских журналах (напр. «Творба»), где Вайл сообщает о строительстве московского метро, у него начинает проявляться его характерный стиль, подчеркивающий работу и усилие конкретного человека, а также постоянное сосредоточение в большей степени на повседневных деталях, нежели на идейной мотивировке. Несмотря на определенным образом лексически и стилистически окрашенный язык данных статей, Вайл постепенно нарушает характерную для этого времени мажорную тональность текстов. В одной из его первых статей под названием «Строительство подземной дороги в Москве» Вайл пишет: «Героизм советского строительства - это не героизм на баррикадах. Это скучная заметка в газете - фабрика «Парижская коммуна» выполнила свой план, добыча угля выросла на 2 процента, стройка новой башни для добычи в Баку, колхоз «Красный маяк» сдал столько и столько хлеба. Среди таких заметок можно найти и новости о Метрострое. Их не сопровождает «марш ударных бригад», и стихи про них тоже не сочиняют. Но все-таки этот героизм можно сравнить с героизмом тех, кто погиб за социализм, за коммуну на северных, южных, восточных и западных фронтах Гражданской войны, тех, кто шел на смерть весенним, летним, осенним и зимним утром и вокруг кого 
кипела жизнь, которую они уже никогда не смогли бы увидеть...» [WEIL 1933, $652]$.

Нельзя не заметить, что у Вайла начинает постепенно проявляться негативное и критическое настроение в отношении советской конъюнктуры. Критические пассажи обнаруживаются прежде всего в его частной переписке, где он жалуется на монотонную, утомляющую работу в издательстве и принудительную ангажированность. Кроме того, в обнаруженных в Литературном архиве Памятника национальной письменности письмах (напр. переписка с С. Бартаковой, С. Вондрачковой, Д.Йеленовой, В. Каплицким), чувствуется тоска по повседневности, по «европейскому», и эта тоска, но прежде всего критика, по-видимому, и стала причиной его увольнения из издательства и вынужденного переселения в колонию чехословацкого промыслового кооператива «Интергельпо» в Иссык-Куле (более подробную информацию о данном периоде жизни Вайла можно найти в статье M. Крыла: Fiř́ Weil - jeden český židovský osud).

Еще до своего отъезда Вайл успевает встретится со своим другом, архитектором Яромиром Крейсаром, который относится к числу наиболее значительных в Чехословакии сторонников авангардной архитектуры, в том числе школы Баухаус, и к пионерам теории функционализма как параллели социально справедливого общества в объектах, предназначенных для отдыха, культуры и жилья [ROUSOVÁ, DUFEK 200, 197]. В то время Крейцар совместно с Йозефом Шпалеком работает над проектом санатория Наркомтяжпрома в Кисловодске, который осуществлялся под руководством братьев Весниных и Гинзбурга [DOFKOVÁ 2016, 103]. Опыт Вайла и Крейцара можно коротко охарактеризовать как опыт разочарования. Сам Крейцар негативное впечатление от работы в сфере архитектуры, постоянных препятствий и апатии лаконично резюмирует следующим образом: «Тот, кто побывал в Союзе три недели, способен написать трехтомный труд, тот, кто побывал в Союзе три месяца, способен написать маленькую брошюрку. И тот, кто побывал там три года, не напишет ничего» [ŠVÁCHA 1995, 143].

Символический конец русского периода Вайла представляет собой работа над романом «Москва-граница» (1937), который был после издания внезапно раскритикован не только из-за критического отношении к советской власти и «мещанско-клеветнического» сюжета, а также из-за формы романа, не соответствующей эстетическим и политическим нормам 30-х годов. Насколько проблематична судьба романа демонстрирует тот факт, что первое чешское переиздание стало возможным только в 1991 г. (до того момента роман был издан только в самиздате в 1978 г.). Уникальность романа заключается прежде всего в том, что читателю представляется, по сравнению с политически ориенти- 
рованными публицистическими репортажами других левых авторов, открытое свидетельство о повседневной жизни чешских эмигрантов в Москве в период сталинских чисток после убийства Кирова. Трагедия Гелены Фришеровой (см. Дни моей жизни, 2017), выступающей под именем Ри, и собственный опыт Вайла развертываются в нескольких эпизодах, образующих каркас данного романа. Автор наслаивает сюжет на фактическую документацию, благодаря которой возникает документально-репортажная форма, типичная для авангардной прозы [GREBENÍČKOVÁ 1968, 367]. Любопытно, что сам Вайл априори не претендует на открытую и элементарную критику советского режима, она формируется самостоятельно с помощью изображения параллельных самостоятельных точек зрения, стремящихся показать детали московской повседневной реальности (транспортные проблемы, отсутствие товаров, суета).

Таким образом, русский - или точнее московский - период представляет, с одной стороны, довольно типичную для Вайла метаморфозу мнений, взглядов и убеждений левых интеллектуалов, и одновременно новое, для данного времени нетрадиционное, стремление показать повседневную жизнь в советской России с точки зрения не массового, а скорее индивидуального взгляда. Подобный анализ может в будущем обогатить дискуссию о феномене Москвы как космополитического и интернационального центра советской России.

\section{Библиография:}

DAVID-FOX, M. (2011): Showcasing the Great Experiment: Cultural Diplomacy and Western Visitors to the Soviet Union, 1921-1941. Oxford.

DOFKOVÁ, J. (2016): Avantgarda 20.-3o. let - Praha a Moskva. Brno.

GREBENÍČKOVÁ, R. (1968): Weilova Moskva-hranice. HD 1968, č. 6.

Kmen: časopis pro moderní literaturu. 1929, s. 53-54.

KRYL, M. (2006): Fiří Weil - jeden českýžidovský osud. In: RANDÁK, J., KOURA, P. (eds):

Hrdinství a zbabělost v české politické kultuře 19. a 20. století. Praha, s. 245-269.

LA PNP, fond Felix Vodička, Tři setkání s Majakovským, nedatováno. (Pamjatnik nacional'noj pismennosti, fond Feliks Vodička, Tri vstreči s Majakovskim).

MAJAKOVSKIJ, V.V. (1958): Nemnogo o čeche. In: Polnoje sobranije sočinenij: V trinadcati tomach. 1955-1961. T. 8. Stichotvorenija 1927 goda, poèma «Chorošo!» i očerki. Moskva, c. 339-341.

NEZVAL, V. (1978): Z mého života. Praha. 
ROUSOVÁ, H., DUFEK, A. (2002): Vademecum: moderní umění v Čechách a na Moravě (1890-1938). Praha.

ŠVÁCHA, R. (1995): Život a dílo architekta f. Krejcara. In: Jaromír Krejcar 1895-1949. Praha, 249.

Tvorba: List pro kritiku a umèní. 1933.

VONDRÁČKOVÁ, J. (2014): Mrazilo - tálo: (o fiřím Weilovi). Praha.

WEIL, J. (1924): Ruská revoluční literatura. Praha.

WEIL, J. (1966): Busta básníkova. In: Hodina zkoušky, hodina pravdy. Praha, s. 12-18.

\section{About the author}

René Andrejs, Palacký University Olomouc, Faculty of Arts, Department of Slavonic Studies, Olomouc, Czech Republic, rene.andrejs01@upol.cz 